\title{
Population Structure of Pythium ultimum from Greenhouse Floral Crops in Michigan
}

\author{
Johanna Del Castillo Múnera, ${ }^{1}$ Lina M. Quesada-Ocampo, ${ }^{2}$ Alejandro Rojas, ${ }^{3}$ Martin I. Chilvers, ${ }^{4}$ and Mary K. Hausbeck ${ }^{4}+$ \\ ${ }^{1}$ Department of Plant Pathology, University of California, Davis, 95616; ${ }^{2}$ Department of Plant Pathology, North Carolina State \\ University, Raleigh, 27695; ${ }^{3}$ Department of Plant Pathology, University of Arkansas, Fayetteville, AR 72701; ${ }^{4}$ Department of \\ Plant, Soil and Microbial Sciences, Michigan State University, East Lansing, 48824
}

\begin{abstract}
Pythium ultimum causes seedling damping-off and root and crown rot in greenhouse ornamental plants. To understand the population dynamics and assess population structure of P. ultimum in Michigan floriculture crops, simple sequence repeats (SSRs) were developed using the previously published $P$. ultimum predicted transcriptome. A total of 166 isolates sampled from 2011 to 2013 from five, one, and three greenhouses in Kalamazoo, Kent, and Wayne Counties, respectively, were analyzed using six polymorphic and fluorescently labeled SSR markers. The average unbiased Simpson's index $\left(\lambda_{u}, 0.95\right)$, evenness $\left(E_{5}, 0.56\right)$, and recovery of 12 major clones out of the 65 multilocus genotypes obtained, suggests that $P$. ultimum is not a recent introduction

into Michigan greenhouses. Analyses revealed a clonal population, with limited differentiation among seasons, hosts, and counties sampled. Results also indicated the presence of common genotypes among years, suggesting that sanitation measures should be enhanced to eradicate resident $P$. ultimum populations. Finally, the presence of common genotypes among counties suggests that there is an exchange of infected plant material among greenhouse facilities, or that there is a common source of inoculum coming to the region. Continued monitoring of pathogen populations will enhance our understanding of population dynamics of $P$. ultimum in Michigan and facilitate improvement of control strategies.
\end{abstract}

In Michigan, floriculture ranks fourth in agriculture industry cash receipts (USDA 2016b), and the state ranks third in the United States for the wholesale value (\$398 million) of floriculture products (USDA 2016a). Pythium root rot is not a new disease, yet it remains a challenge for greenhouse growers. In ornamental plants, Pythium ultimum causes seed rot, root rot, seedling damping-off, and rot of lower stems (Garzón et al. 2011; Moorman et al. 2002). In Michigan, $P$. ultimum was reported as the second most common Pythium species infecting floriculture crops, after $P$. irregulare, and it is highly virulent on geranium seed and seedlings (Del Castillo Múnera and Hausbeck 2016; Stephens and Powell 1982). Interestingly, $P$. ultimum has not been a prevalent species in other states as it was in Michigan (Garzón et al. 2014; Lookabaugh et al. 2015; Moorman et al. 2002). P. ultimum is a homothallic self-fertile oomycete (Francis et al. 1994; van der Plaats-Niterink 1981) able to reproduce asexually through the formation of asexual sporangia or hyphal swellings (Martin and Loper 1999; Schroeder et al. 2013).

$P$. ultimum encompasses a species complex in which two morphological groups are differentiated based on their ability or lack thereof to form zoospores (P. ultimum var. sporangiiferum and $P$. ultimum var. ultimum, respectively) (van der Plaats-Niterink 1981). Francis et al. (1994) found that there is not a clear genetic differentiation among homothallic and hyphal swelling isolates of $P$. ultimum var. ultimum and P. ultimum var. sporangiiferum. Later, Barr et al. (1997) found little genetic variation of P. ultimum based on isozymes, although three main clusters were differentiated. A more recent study of the $P$. ultimum species complex based on a multigene

${ }^{\dagger}$ Corresponding author: M. K. Hausbeck; E-mail: hausbec1@msu.edu

Funding: This research is based upon work supported by Specific Cooperative Agreement 58-1907-0-096 with USDA-ARS under the Floriculture and Nursery Research Initiative, and by the American Floral Endowment.

* The $\boldsymbol{e}$-Xtra logo stands for "electronic extra" and indicates that three supplementary figures and one supplementary table are published online.

Accepted for publication 11 October 2018.

C 2019 The American Phytopathological Society phylogeny (Eggertson 2012) described four distinct species: $P$. ultimum, P. sporangiiferum, Pythium sp. nov. 1, and Pythium sp. nov. 2.

Studies of Pythium spp. populations associated with ornamental crops have been conducted in some U.S. states. Weiland et al. (2015) studied the population structure of $P$. ultimum, $P$. irregulare, and $P$. sylvaticum from nursery soils in Oregon using single sequence repeats (SSRs) and amplified fragment length polymorphisms (AFLPs). In their study, a significant differentiation among populations of $P$. irregulare and $P$. sylvaticum isolated from different nurseries was found, but geographic differentiation within the $P$. ultimum populations was not detected. A study of $P$. aphanidermatum from commercial greenhouses in Pennsylvania using AFLP and SSRs found that $P$. aphanidermatum was differentiated into three genetic groups, and that there was gene flow among isolates from different greenhouses (Lee et al. 2010). In Michigan greenhouses, it is unknown how $P$. ultimum populations are structured. It is presumed that there are shared genotypes among counties, but this has not been evaluated.

The study of population dynamics can provide insight into the life history and evolutionary pattern of plant pathogens and can be used to develop management strategies (Grünwald and Goss 2011; Linde et al. 2002; McDonald and Linde 2002). One common analytical approach is the use of microsatellites (SSRs) (Guichoux et al. 2011; Li et al. 2013), which are codominant markers characterized by a high degree of polymorphism and high allelic diversity, and they are informative for the analysis of individual isolates in a population (Cooke and Lees 2004; Ellegren 2004). Reduced costs in next-generation sequencing and the availability of open-source software and data sets allow the identification of SSR loci from genome or transcriptome sequences. In addition, cost-effective genotyping platforms that analyze multiple SSR loci at one time allow efficient and robust analysis of pathogen populations (Guichoux et al. 2011; Hayden et al. 2008; Li et al. 2013). In the case of the floriculture industry in Michigan, the development of SSRs in P. ultimum would provide management tools to monitor the presence of the pathogen. Specifically, it would help to determine if $P$. ultimum populations recovered are genetically homogeneous over time, which would suggest that persistent populations are not eradicated with the current control strategies.

In the present study, a set of novel SSRs was developed using available transcript data (Lévesque et al. 2010) with the ultimate goal 
of assessing the population structure of $P$. ultimum sensu lato isolates collected from greenhouse floral crops in Michigan from 2011 to 2013 (Del Castillo Múnera and Hausbeck 2016). Specifically, we aimed to (i) develop SSR markers for population genetics analysis, (ii) assess the degree of genotypic diversity and clonality of the $P$. ultimum population associated with floral crops in the region, and (iii) determine if population differentiation exists within or between location, host, and season.

\section{Materials and Methods}

Plant sampling. Potted poinsettias (Euphorbia pulcherrima) with root rot symptoms were sampled from nine greenhouses located in Kalamazoo (number of greenhouses $[\mathrm{ng}]=3$ ), Kent $(\mathrm{ng}=3$ ), and Wayne (ng = 3) during the months of October and November in 2011 and 2012. Symptomatic geranium (Pelargonium $\times$ hortorum) plants were sampled from 12 greenhouses located in Kalamazoo $(n g=5)$, Kent $(n g=4)$, and Wayne (ng = 3) Counties during March and April of 2012 and 2013. Roots of symptomatic plants were rinsed under running tap water, cut into 0.8 -cm lengths, air dried, and four root pieces were placed on three replicate plates per plant sampled on corn meal agar (CMA) amended with ampicillin $(0.25 \mathrm{mg} / \mathrm{liter})$, rifampicin $(0.01 \mathrm{~g} /$ liter $)$, pentachloronitrobenzene $(0.1 \mathrm{~g} /$ liter $)$, and benomyl (0.05 g/liter) (Ghimire et al. 2009). Suspect isolates of Pythium spp. were initially confirmed via microscopic observation of oogonia and sporangia following the van der PlaatsNiterink (1981) identification key, and mycelial growth was transferred and purified on amended CMA. After $48 \mathrm{~h}$, an actively growing hyphal tip from each isolate was transferred to CMA to establish a single hyphal tip culture. For long-term storage, three small blocks $\left(0.49 \mathrm{~cm}^{2}\right)$ from a 1-week-old culture were placed into $1.5-\mathrm{ml}$ microtubes containing sterile distilled water and hemp seeds and stored at $20^{\circ} \mathrm{C}$.

$P$. ultimum collection and identification. Plugs $\left(0.49 \mathrm{~cm}^{2}\right)$ of actively growing mycelia from pure cultures were placed in 9-cm Petri dishes containing V8 broth (163 ml of filtered V8 juice, $3 \mathrm{~g}$ of $\mathrm{CaCO}_{3}, 1$ liter of distilled water, $0.25 \mathrm{ml} /$ liter of ampicillin, and $0.01 \mathrm{~g} /$ liter of rifampicin) (Del Castillo Múnera and Hausbeck 2016) for 1 week at $20^{\circ} \mathrm{C}$. Mycelia were harvested with sterile tongue depressors, placed in $1.5-\mathrm{ml}$ microtubes, frozen at $-20^{\circ} \mathrm{C}$, and lyophilized. DNA extraction was performed using the AutoGen 850 system (AutoGen, Holliston, MA) at the Research Technology Support Facility (Michigan State University, East Lansing, MI). DNA was quantified with a NanoDrop Spectrophotometer ND1000 (Thermo Scientific, Wilmington, DE).

Molecular identification was performed using the internal transcribed spacer (ITS) region of the ribosomal DNA. ITS was amplified with the ITS4 and ITS5 primers (White et al. 1990). Additional amplification of the mitochondrial gene cytochrome oxidase II (cox II) was performed on 100 isolates selected from different genotypes using the FM58 and FM66 primers (Martin 2000). Reactions consisted of $2 \mathrm{mM} \mathrm{MgCl}_{2}, 1 \times$ buffer, $0.2 \mu \mathrm{M} \mathrm{dNTPs,} 0.2 \mu \mathrm{M}$ of each primer (for each set of ITS/cox II), $1 \mathrm{U}$ of Taq polymerase, and $1 \mu \mathrm{l}$ of DNA $(50 \mathrm{ng}$ ) in a $25-\mu \mathrm{l}$ reaction volume. Amplifications were performed on a Mastercycler thermal cycler (Eppendorf, Westbury, NY) with initial denaturation at $96^{\circ} \mathrm{C}$ for $3 \mathrm{~min}$, followed by 35 cycles of $96^{\circ} \mathrm{C}$ for $1 \mathrm{~min}, 55^{\circ} \mathrm{C}$ for $1 \mathrm{~min}$, and $72^{\circ} \mathrm{C}$ for $2 \mathrm{~min}$, and a final extension at $72^{\circ} \mathrm{C}$ for $10 \mathrm{~min}$. Samples were visualized by $1 \%$ agarose gel electrophoresis stained with ethidium bromide and documented using Quantity One software (Bio-Rad, Hercules, CA). PCR products were purified with the Exo-Sap kit (Thermo Fisher Scientific, CA), by adding $1 \mu \mathrm{l}$ of exonuclease I and $2 \mu \mathrm{l}$ of shrimp alkaline phosphatase. Samples were incubated at $37^{\circ} \mathrm{C}$ for $15 \mathrm{~min}$, and then at $80^{\circ} \mathrm{C}$ for $15 \mathrm{~min}$ to inactivate the enzymes. Amplicons were submitted for sequencing at Macrogen (Rockville, MD). Sequences were assembled in CLC Main Workbench (Qiagen, Germantown, MD) and compared with a local library built with curated sequences from Robideau et al. (2011).

P. ultimum was the second most common (25\%) species isolated from greenhouse floriculture crops in Michigan and was highly virulent (Del Castillo Múnera and Hausbeck 2016). A total of 166
P. ultimum isolates maintained in the laboratory of M. K. Hausbeck at Michigan State University collected during fall (October and November) of 2011 and 2012 and spring (March and April) of 2012 and 2013 were analyzed in this study. From the total number of isolates collected, 148 were obtained during the fall season (2011 and 2012) from poinsettia sampled in Kalamazoo, Wayne, and Kent Counties. A smaller number $(n=18)$ of the isolates were obtained from geranium sampled in Kalamazoo and Wayne Counties during the spring season (2012 to 2013) (Supplementary Table S1). The identification was based on the ITS region having an identity greater than $98 \%$. One hundred thirty-eight Pythium isolates had greater than $98 \%$ ITS identity with $P$. ultimum vouchers CBS39851, Lev1441, CBS72994, BR1038, or CBS122650 (GenBank accession nos. HQ643865, HQ643867, HQ643869, HQ643875, and HQ643865, respectively), and 27 isolates had greater than $98 \%$ ITS identity with $P$. ultimum var. ultimum vouchers BR867, BR768, or BR864 (GenBank accession nos. HQ643885, HQ643919, and HQ643886 respectively). The sequences of the cox II region confirmed the species identification obtained with the ITS region (Del Castillo Múnera and Hausbeck 2016).

To perform a population genetics analysis, three populations were defined. The populations were defined based on the number of isolates recovered per season in each year. However, for spring, the number of isolates was too low to allow population analyses independently for each year, and therefore isolates recovered during spring of 2012 and 2013 were combined into one population. This resulted in the following three populations: (i) fall 2011,83 poinsettia isolates; (ii) spring 2012+2013, 18 geranium isolates; and (iii) fall 2012, 65 poinsettia isolates.

Microsatellite search and selection. To avoid designing microsatellite markers in paralogous genomic regions, putative single-copy genes were identified by performing self-BLASTp analysis of the $P$. ultimum predicted proteome (Lévesque et al. 2010) using a cutoff of 1e-10. BLASTp results were analyzed to retain protein sequences with only one match to the proteome. Gene sequences of these putative single-copy genes were used for SSR identification. Simple and compound SSRs consisting of mono (20 minimum repeats), di- (five repeats), tri- (four repeats), tetra- (three repeats), penta- (three repeats), and hexamers (three repeats) were identified in the publicly available $P$. ultimum transcriptome (Lévesque et al. 2010) with the Microsatellite Identification Tool (PGRC 2002). Flanking primers to amplify identified SSRs were designed using Primer3 (Rozen and Skaletsky 1999). Primer3 was set to design primers between 18 and 27 bp with optimal length of $20 \mathrm{bp}$, GC content between 20 and 80 with optimal GC content of 50, a melting temperature between 57 and $63^{\circ} \mathrm{C}$ with the optimal melting temperature of $60^{\circ} \mathrm{C}$, and the ability to amplify products between 100 and $300 \mathrm{bp}$. A subset of 50 SSRs was selected based on the following criteria: (i) motifs with number of repeats greater than three; (ii) product size between 100 and $300 \mathrm{bp}$; and (iii) location in different scaffolds across the P. ultimum genome, to avoid linked loci.

To select the most polymorphic markers, SSRs were evaluated for DNA samples from eight individual $P$. ultimum isolates collected in this study belonging to different greenhouse locations and hosts. Additionally, a pooled DNA sample was prepared from 50 different P. ultimum isolates. Polymerase chain reaction (PCR) of individual microsatellites consisted of $1 \times$ buffer, $0.2 \mu \mathrm{M}$ dNTPs, $0.2 \mu \mathrm{M}$ of each SSR primer, $0.5 \mathrm{U}$ of Taq polymerase, and $50 \mathrm{ng}$ of DNA $(1 \mu l)$ in a $15-\mu l$ reaction volume. Amplification reactions were performed on a Mastercycler thermal cycler (Eppendorf) with initial denaturation at $94^{\circ} \mathrm{C}$ for $4 \mathrm{~min}$, followed by 30 cycles of $94^{\circ} \mathrm{C}$ for $1 \mathrm{~min}$, annealing temperature at $60^{\circ} \mathrm{C}$ for $45 \mathrm{~s}$, extension at $72^{\circ} \mathrm{C}$ for $1 \mathrm{~min}$, and a final extension at $72^{\circ} \mathrm{C}$ for $10 \mathrm{~min}$. Samples were separated by $3 \%$ MetaPhor agarose (Lonza, Rockland, ME) gel electrophoresis at $100 \mathrm{~V}$ for 3 or $4 \mathrm{~h}$ and visualized with ethidium bromide using Quantity One software (Bio-Rad).

The amplification product of each microsatellite locus obtained with the eight isolates selected was sequenced to confirm that the motif of each microsatellite locus was contained in the PCR products obtained. Resulting sequences were assembled in CLC Main 
Workbench (Qiagen) and compared with BLASTn against the $P$. ultimum genome available in the Pythium genome database (Lévesque et al. 2010).

Microsatellite analyses. A total of six markers showing polymorphism in the initial screening were selected for microsatellite analysis of 166 total $P$. ultimum isolates using fluorescently labeled primers. The forward primers were modified with the dyes HEX, FAM, or NED at the $5^{\prime}$ end, and the reverse primers were modified with a "PIG tail" (GTTT) at the $5^{\prime}$ end (Guichoux et al. 2011) (Table 1). PCR was performed as explained above using 0.5 U of Pfu DNA polymerase (Thermo Scientific, Waltham, MA). Resulting amplification products were visualized by $2 \%$ agarose gels and combined according to different product sizes: (i) PY28, PY55, and PY57, and (ii) PY62, PY69, and PY30 (Table 1). Combined products were subsequently sized by fragment analysis at Macrogen (Seoul, South Korea). SSR profiles generated by fragment analysis were first analyzed using Peak Scanner 2.0 (Applied Biosystem Software) for allele size calling and then using the Tandem software (Matschiner and Salzburger 2009) for allele binning to convert allele sizes into discrete units. To assess if the results obtained were reproducible, the microsatellite analyses were repeated with $50 \%$ of the population evaluated.

Population genetic analyses. Quantitative measures of genetic diversity were estimated using GenAlEx 6.5 (Peakall and Smouse 2012) and consisted of allelic diversity, number of alleles per locus $(\mathrm{Na})$, effective number of alleles $(\mathrm{Ne})$, private alleles, Nei's gene diversity $(h)$, the probability that two randomly selected alleles from a population are different (Nei 1978), and the unbiased gene diversity scaled according to sample size $(u h)$. To determine if the six SSRs evaluated provide enough power to discriminate among individuals of the population, a genotype accumulation curve was generated with the R package poppr version 2.8.0 (Kamvar et al. 2014).

Quantitative measures of genetic diversity including genotypic richness, genotypic diversity, and evenness were estimated using the R package poppr version 2.8.0 (Kamvar et al. 2014). Genotypic richness $(g)$ is the number of genotypes observed within the population, and the expected genotypic richness $(E g)$ measures the number of expected genotypes present at the smallest sample size $(N=18)$ based on rarefaction curves (Grünwald et al. 2003). Genotypic diversity was quantified with Stoddart and Taylor's index $(G)$ (Stoddart and Taylor 1988), which is based on sample size. $\lambda_{u}$ was calculated to obtain a measure of genotypic diversity that is unbiased according to sample size. $\lambda_{u}$ measures the probability that two randomly selected genotypes from a population are different (Nei 1978).
Genotypic evenness $\left(E_{5}\right)$ measures the distribution of genotype abundance within the population (Grünwald et al. 2003; Ludwig 1988).

Populations were clone corrected. For this, the dataset was evaluated as if only one individual per multilocus genotype (MLG) is represented per population (Grünwald and Hoheisel 2006; Milgroom 1996). Clone correction was based on county/season hierarchy, removing duplicated genotypes if these were collected in the same county during the same season. To determine whether the populations are clonal, the index of association $\left(I_{A}\right)$, the standardized index of association $\left(\overline{\mathrm{r}}_{d}\right)$, and the test of significance were estimated on nonclone-corrected and clone-corrected populations in the $\mathrm{R}$ package poppr version 2.8.0 (Kamvar et al. 2014). The $I_{A}$ index evaluates if loci are linked, by comparing the variance of pairwise distance between all individuals within the population under no linkage disequilibrium (Agapow and Burt 2001). Because the $I_{A}$ index depends on the sample size of the loci, the $\bar{r}_{d}$ index was calculated to adjust the number of loci sampled. To determine if the indexes calculated were significant $(P$ value), the test of significance was calculated by randomly permuting the alleles at each locus 1,000 times (Grünwald et al. 2003). Clone-corrected data were used for all the subsequent analyses. To determine the probability that repeated genotypes originated from different sexual reproductive events (Arnaud-Haond et al. 2007), $p_{\text {sex }}$ was estimated in the R package poppr version 2.8.0.

Population structure was analyzed by analysis of molecular variance (AMOVA) (Excoffier et al. 1992), based on the Nei Bruvo distance matrix, in poppr version 2.8.0 (Kamvar et al. 2014). The data set was arranged into three hierarchical levels: county, season, and host. AMOVA estimates the number of differences summed over loci based on a matrix of distances between individuals. Covariance components and fixation indices $(\Phi)$ were calculated for each hierarchical level. The significance of fixation indices was calculated by 1,000 random permutations (Grünwald and Hoheisel 2006). The level of genetic flow among populations $(\mathrm{Nm})$ was calculated using POPGENE version 3.1 (Yeh et al. 1997). Minimum spanning networks (MSN) were generated across populations by Bruvo's genetic distance, which is based on a stepwise mutation model for microsatellites (Bruvo et al. 2004). A discriminant analysis of principal components (DAPC) was constructed implementing adegenet version 2.1.0 (Jombart 2008). This analysis is suitable for clonal populations and uses a multivariate approach to infer the number of clusters in a population (Milgroom 1996). An unweighted pair group method with an arithmetic mean (UPGMA) unrooted tree and a neighbor joining (NJ) tree were generated based on Bruvo's genetic

Table 1. Characteristics of the simple sequence repeat (SSR) loci developed and utilized to evaluate Pythium ultimum populations from greenhouse floral crops in Michigan

\begin{tabular}{|c|c|c|c|c|c|}
\hline \multirow[b]{2}{*}{ SSR locia } & \multirow[b]{2}{*}{ Repeat motif ${ }^{b}$} & \multirow[b]{2}{*}{ Primer sequence $\left(5^{\prime} \text { to } 3^{\prime}\right)^{\mathrm{c}}$} & \multirow[b]{2}{*}{ Gene ID ID $^{\mathbf{d}}$} & \multicolumn{2}{|r|}{ Alleles $^{\mathbf{e}}$} \\
\hline & & & & $N$ & Size (bp) \\
\hline \multirow[t]{2}{*}{ PY28 } & $(\mathrm{CTG})_{4}$ & F: [HEX] ATGTCGTCAACGGTGTGGTC & PYU1_T008001 & 6 & $497,499,501,503,509,511$ \\
\hline & & R: GTTTGGATGTCGACGCCTGAGTAG & & & \\
\hline \multirow[t]{2}{*}{ PY30 } & $(\mathrm{GCTCCT})_{3}$ & F: [HEX] AAGCGATTGTGGAGAAGCGA & PYU1_T009522 & 3 & $418,424,430$ \\
\hline & & R: GTTTTTGGAGGAGTTGCAGCTTGT & & & \\
\hline \multirow[t]{2}{*}{ PY55 } & $(\mathrm{GT})_{10}$ & F: [FAM] GCAATGCACGCTCTCTATGG & PYU1_T002451 & 5 & $161,163,167,171,173$ \\
\hline & & R: GTTTGCTGGATCATAGAGCGCTGT & & & \\
\hline \multirow[t]{2}{*}{ PY57 } & $(\mathrm{TCT})_{7}$ & F: [NED] GACTTTGAGGACGACCAGCA & PYU1_T004435 & 3 & $195,201,537$ \\
\hline & & R: GTTTCTCTCTTTCGCTGCCGTTTG & & & \\
\hline \multirow[t]{2}{*}{ PY62 } & $(\mathrm{TCG})_{7}$ & F: [ FAM] GTTCCTGCGCATTCATCGTC & PYU1_T002941 & 4 & $164,167,170,173$ \\
\hline & & R: GTTTACCATGAGTCCTGGCCATTG & & & \\
\hline \multirow{2}{*}{ PY69 } & $(\mathrm{CAAAGC})_{3}$ & F: [NED] GAACCTCGGTATCAGCTCGG & PYU1_T011952 & 3 & $284,290,296$ \\
\hline & & R: GTTTCCGATTCATCCGAGATCGCA & & & \\
\hline
\end{tabular}


distance. The MSN, DAPC, UPGMA, and NJ tree were generated using poppr version 2.8.0 (Kamvar et al. 2014). All analyses and code used in $\mathrm{R}$ are available at the following repository: https://github. com/jdelcastillo1/Pythium_Pop, doi.org/10.5281/zenodo.1405257.

\section{Results}

Microsatellite search and selection. A total of 2,060 microsatellites were found in the $P$. ultimum transcriptome (Lévesque et al. 2010). Trinucleotide repeats were the most common (76\%), followed by dinucleotide repeats (20\%), with the motifs CAG and GC being the most abundant, respectively. Most of the SSR loci tested did not show variability among isolates, nor multiple bands in the DNA pool from 50 isolates; only six out of 50 SSRs tested were polymorphic in the subset of isolates selected for the initial screen for polymorphism. The sequences of the amplification product of each SSR locus confirmed the presence of each SSR motif at different scaffolds of the $P$. ultimum transcriptome. These six polymorphic markers (Table 1) were selected to evaluate the 166 P. ultimum isolates collected from greenhouse floral crops in Michigan. The expected amplification products for all markers were consistent with the alleles observed (Table 1), with the exception of the markers PY28 and PY30, for which the allele sizes obtained were greater than expected. This difference in size was likely owing to the presence of an intron, given that the microsatellites were obtained from the transcriptome. The number of alleles obtained for each SSR locus ranged from three to six (Table 1). The genotypic accumulation curve using the six markers showed that more than $90 \%$ of unique MLGs present in the sample could be discriminated among the 166 individuals analyzed (Supplementary Fig. S1).

Table 2. Genetic diversity of Pythium ultimum populations from floral crops in Michigan, where each population represents isolates obtained during fall and spring seasons from 2011 to 2013 analyzed with six simple sequence repeat loci

\begin{tabular}{llllcccc}
\hline Population $^{\mathbf{a}}$ & $\boldsymbol{N}$ & $\boldsymbol{N a}^{\mathbf{b}}$ & $\boldsymbol{N e}^{\mathbf{c}}$ & Private alleles $^{\mathbf{d}}$ & $\boldsymbol{H o}^{\mathbf{e}}$ & $\boldsymbol{h}^{\mathbf{f}}$ & $\boldsymbol{u h}^{\mathbf{g}}$ \\
\hline Fall 2011 & 83 & 3.33 & 2.48 & 0.17 & 0.58 & 0.52 & 0.52 \\
Spring 2012+2013 & 18 & 2.83 & 1.42 & 0 & 0.19 & 0.27 & 0.28 \\
Fall 2012 & 65 & 3.50 & 2.41 & 0.33 & 0.47 & 0.53 & 0.54 \\
Mean & 55.33 & 3.22 & 2.10 & 0.25 & 0.42 & 0.44 & 0.45 \\
\hline
\end{tabular}

a Population denoted by sampling season, host indicated in parentheses: fall 2011 (poinsettia), spring 2012+2013 (geranium), and fall 2012 (poinsettia).

${ }^{\mathrm{b}} \mathrm{Na}=$ observed number of alleles.

${ }^{\mathrm{c}} \mathrm{Ne}=$ effective number of alleles.

${ }^{\mathrm{d}}$ Number of alleles unique to the individual population.

e Observed genetic diversity (heterozygosity).

${ }^{\mathrm{f}}$ Nei's gene diversity $(h)$, the probability that two randomly selected alleles from a population are different (Nei 1978).

${ }^{g}$ Unbiased gene diversity $(u h)$ scaled to sample size.
Population genetic diversity. In the three populations evaluated (fall 2011, spring $2012+2013$, and fall 2012), all six SSR loci were polymorphic. The estimated number of different alleles per locus ranged from 2.83 to 3.33 , and the number of effective alleles ranged from 1.42 to 2.48 (Table 2 ). The population with the highest number of isolates $(n=83)$ was collected in fall 2011 and contained the highest number of effective alleles. There were no unique alleles detected for the spring population, but a small number were found for fall 2011 and fall 2012 populations (Table 2). The average Nei's gene diversity $(h)$ for the three populations was 0.44 , with the highest gene diversity observed in fall 2012 and fall 2011 populations. The unbiased gene diversity $(u h)$ values were the same as the $h$ values obtained.

Although the $P$. ultimum population appears to be genetically diverse, with 65 MLGs detected, it appeared to be clonal. The index of association $\left(I_{A}\right)$ and the standardized index of association $\left(\bar{r}_{d}\right)$ were significantly different from zero $(P=0.001)$ for all individuals and for the clone-corrected data based on season/county hierarchy. The $\bar{r}_{d}$ was 0.28 for fall 2011 and fall 2012 populations and 0.26 for the spring $2012+2013$ population, including all the individuals. For the clone-corrected data, the $\bar{r}_{d}$ ranged from 0.17 (fall 2011) to 0.22 (fall 2012) (Table 3), indicating that the loci within the population were linked and rejecting the hypothesis of random mating. The probability that a repeated genotype originated from different sexual reproductive events, $p_{\text {sex }}$, was lower than $\alpha=0.05$ for 81 and $68 \%$ of all individuals and for the clone-corrected data, respectively, corroborating the clonality of the population (Supplementary Fig. S2).

Population genotypic diversity and differentiation. A total of 65 MLGs were observed across the three populations (fall 2011, spring 2012+2013, and fall 2012), ranging from 14 to 40 MLGs per population (Table 3). For the fall 2011 population, 10 MLGs were recovered more than once, grouping clonal individuals. The most frequent MLG, MLG.33, encompassed more than 15 individuals (Fig. 1). For the spring $2012+2013$ population, four MLGs had two individuals per clonal group. For the fall 2012 population, 11 MLGs grouped more than three individuals, with MLG. 10 representing 15 individuals only found in this population (Fig. 1). For each population (fall 2011, spring $2012+2013$, and fall 2012), the percentage of unique genotypes was 74,71 , and $50 \%$, respectively. Across the three populations, only $24 \%$ of the MLGs present were unique. Forty percent of the total individuals were represented in MLGs that were commonly found among the populations established by season and among the places of origin. A total of five MLGs (MLG.14, MLG.23, MLG.33, MLG.55, and MLG.65) were shared by fall 2011 and spring 2012+2013 populations, four MLGs (MLG.1, MLG.15, MLG.28, and MLG.47) were shared by fall 2011 and 2012 populations, and MLG.24 was present in all three populations (Fig. 2). Summarized by location, one MLG (MLG.23) was present in Kalamazoo and Kent Counties, and four MLGs (MLG.10, MLG.14, MLG.24, and MLG.44) were present in Kalamazoo and

Table 3. Analysis of genotypic diversity and index of association with all individuals and with clone-corrected data of Pythium ultimum populations from floriculture crops in Michigan using six simple sequence repeat loci

\begin{tabular}{|c|c|c|c|c|c|c|c|c|c|c|}
\hline \multicolumn{9}{|c|}{ All individuals } & \multicolumn{2}{|c|}{ Clone-corrected } \\
\hline Population $^{\mathbf{a}}$ & $N$ & $g^{\mathbf{b}}$ & $E g^{\mathbf{c}}$ & $G^{\mathbf{d}}$ & $\lambda_{u}{ }^{\mathrm{e}}$ & $E_{5} \mathrm{f}$ & $I_{A}{ }^{g}$ & $\overline{\overline{\mathbf{r}}_{d}^{\mathbf{h}}}$ & $I_{A}{ }^{\mathrm{g}}$ & $\overline{\overline{\mathbf{r}}_{d}^{\mathrm{h}}}$ \\
\hline Fall 2011 & 83 & 40 & 12.21 & 11.30 & 0.92 & 0.49 & $1.26^{*}$ & $0.28^{*}$ & $0.77 *$ & $\overline{0.17 *}$ \\
\hline Spring $2012+2013$ & 18 & 14 & 14.0 & 12.51 & 0.97 & 0.93 & $1.32 *$ & $0.28 *$ & $1.04 *$ & $0.22 *$ \\
\hline Fall 2012 & 65 & 22 & 11.13 & 10.53 & 0.91 & 0.68 & $1.25^{*}$ & $0.26^{*}$ & $0.91^{*}$ & $0.18 *$ \\
\hline Total & 166 & 65 & 13.80 & 21.46 & 0.95 & 0.56 & $1.19^{*}$ & $0.25^{*}$ & $0.91^{*}$ & $0.19 *$ \\
\hline
\end{tabular}

a Population denoted by sampling season, host indicated in parentheses: fall 2011 (poinsettia), spring 2012+2013 (geranium), and fall 2012 (poinsettia).

${ }^{b}$ Genotypic richness: number of genotypes observed in the population.

${ }^{\mathrm{c}}$ Expected genotypic riches: number of expected genotypes present at the smallest sample size $(N=18)$ based on rarefaction curves.

d Genotypic diversity calculated with the Stoddart and Taylor's index.

e Simpson's index scaled to sample size.

${ }^{\mathrm{f}}$ Genotypic evenness measures the distribution of genotype abundance in the population.

g Index of association test for linkage disequilibrium for all individuals and for clone-corrected data, where an asterisk indicates statistical significance $(P=0.001)$ compared with 1,000 randomizations.

${ }^{\mathrm{h}}$ Standardized index of association for all individuals and for clone-corrected data, where an asterisk indicates statistical significance $(P=0.001)$ compared with 1,000 randomizations. 


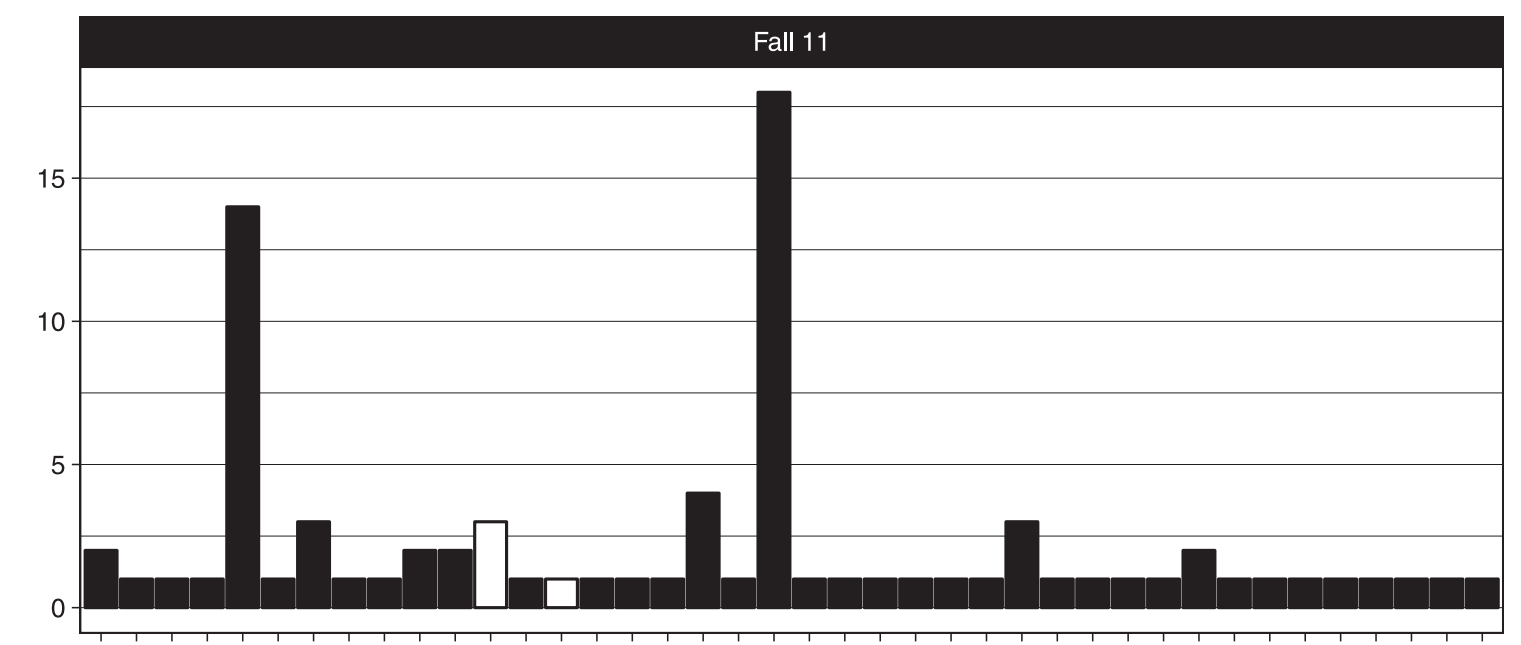

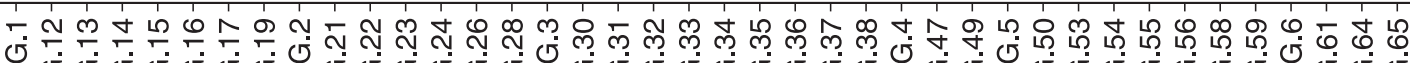

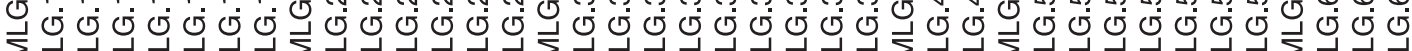

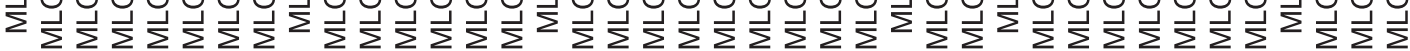

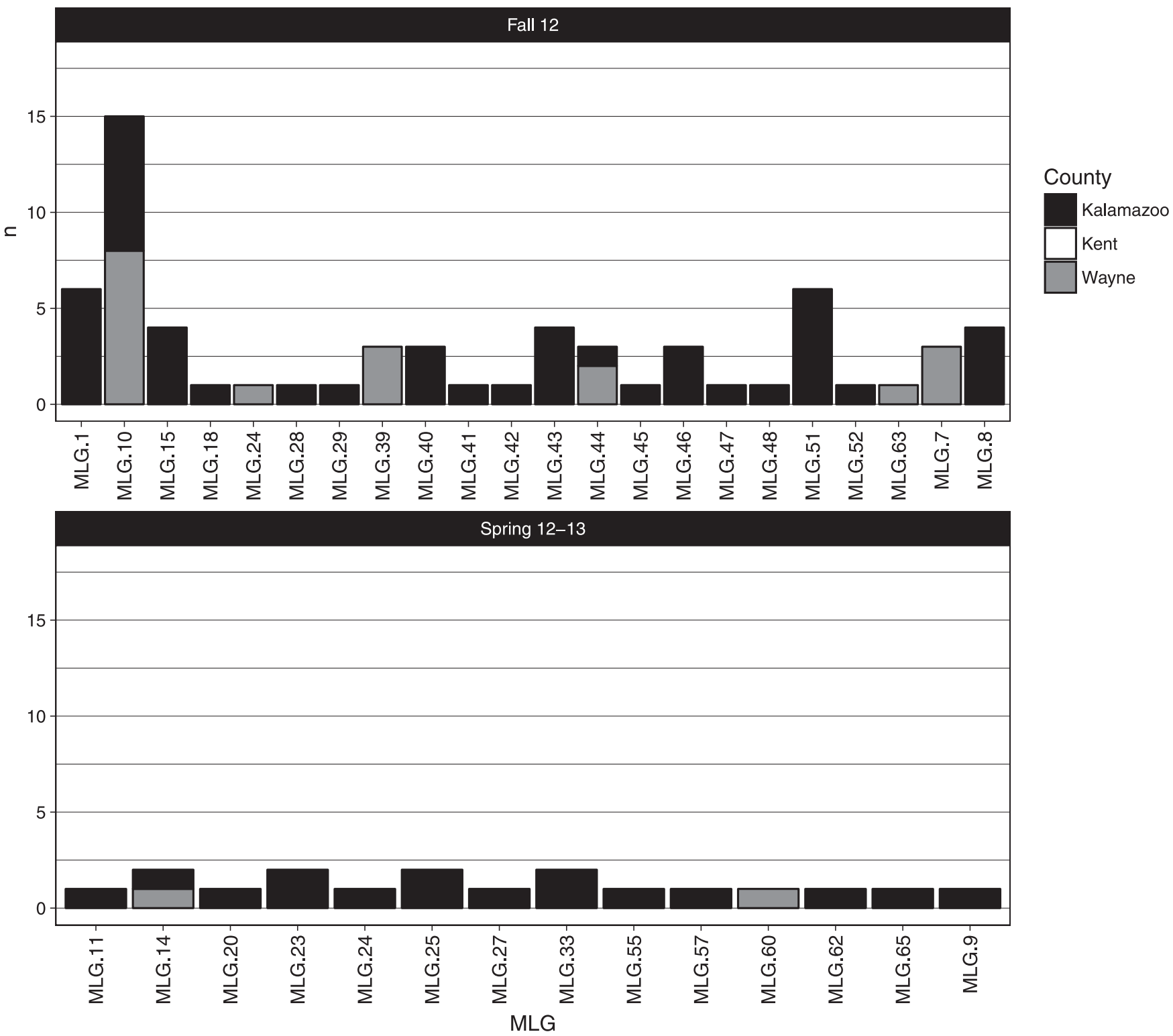

Fig. 1. Frequency distribution of Pythium ultimum genotypes detected in fall of 2011, spring of 2012+2013, and fall of 2012 from greenhouse floral crops in Kalamazoo, Kent, and Wayne Counties. 
Wayne Counties (Fig. 1). Genotypic evenness ranged from 0.49 for the fall 2011 population to 0.93 for the spring $2012+2013$ population, showing that the genotypes were fairly evenly distributed for the three populations. The genetic richness expected with the smallest sample size $(n=18)$ ranged from 14.0 (spring 2012+2013) to 11.13 (fall 2012). The genotypic diversity scaled to sample size (unbiased Simpson's index, $\lambda_{u}$ ), averaged 0.938 , with fall 2012 having the lowest diversity (0.91) and spring 2012+2013 the highest (0.97) (Table 3).

Populations were not significantly differentiated among seasons, hosts, counties, and among samples within populations based on clone-corrected data (Table 4). A total of $84 \%$ of variation was observed within samples (samples within greenhouses), 7\% among samples within seasons, and $3 \%$ among counties (Table 4). Fixation indices were low, being lowest among counties, $\Phi=0.02(P=$ $0.153)$, and highest within samples, $\Phi=0.15(P=0.042)$. The gene flow estimate was $\mathrm{Nm}=3.01$, suggesting genetic exchange among the populations. A lack of population differentiation was observed in the minimum-spanning network (Fig. 2), in which each node represented the most frequent MLGs or a unique genotype from fall 2011, spring 2012+2013, and fall 2012 populations; the nodes were closely related and spread across the minimum-spanning network clusters. The three assigned clusters did not group the MLGs by population (fall 2011, spring 2012+2013, and fall 2012). The clusters obtained with the DAPC also revealed that the fall 2011, spring
2012+2013, and fall 2012 individuals collected from greenhouses in Kalamazoo, Kent, and Wayne Counties did not form differentiated groups. To look for further population differentiation, additional DAPC analyses were performed among locations (Kalamazoo, Kent, and Wayne); the clusters obtained showed that individuals recovered from Kent County differentiated from the ones recovered in Kalamazoo and Wayne Counties (Fig. 3). The NJ tree (Supplementary Fig. S3) also showed that the $P$. ultimum population evaluated was not differentiated based on the two species complexes analyzed: $P$. ultimum and $P$. ultimum var. ultimum.

\section{Discussion}

Analysis of genetic variation among $P$. ultimum isolates recovered from ornamental greenhouse crops in Michigan using six microsatellite loci revealed limited differentiation among isolates grouped by season, host, and county. Data are consistent with exchange of infected plant material among greenhouse facilities, or a common source of inoculum infecting plants in greenhouses located in Kalamazoo, Kent, and Wayne Counties. The interchange of infected plant material has been previously reported in the region with Phytophthora nicotianae and Phytophthora drechsleri infecting ornamental crops (Duniway 1977).

Fifteen percent of MLGs (10 MLGs) that grouped $40 \%$ of the total isolates were recovered repeatedly during the seasons sampled, but
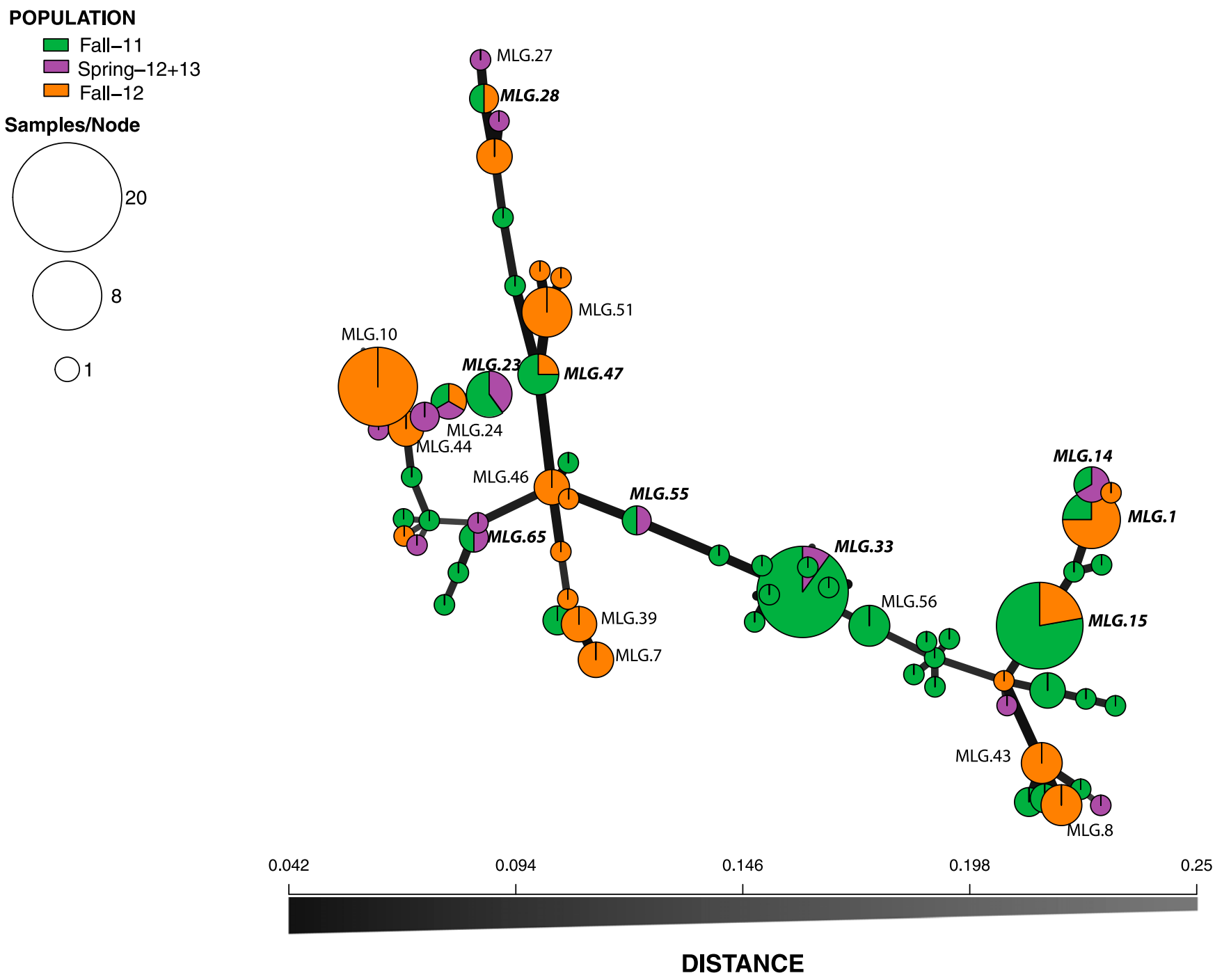

Fig. 2. Minimum spanning network for Pythium ultimum multilocus genotypes from Michigan. Each node (circle) represents a multilocus genotype. Distances between nodes are proportional to Bruvo's distance (Bruvo et al. 2004). Node sizes and numbers within nodes are indicators of frequency, colors indicate proportion of their frequencies in designated populations fall 2011 (green), spring $2012+2013$ (purple), and fall 2012 (orange). All the samples from fall were recovered from poinsettia, and all the samples from spring were recovered from geranium. 
29 of 40 MLGs obtained in the first sampling season of fall 2011 were not detected in later sampling efforts. The presence of common genotypes among years suggests that the control strategies that are being implemented in the greenhouse facilities are not sufficient to eradicate $P$. ultimum. Commonly, $P$. ultimum is controlled in greenhouses with fungicides including mefenoxam (Daughtrey and Benson 2005; Hausbeck and Harlan 2013; Moorman et al. 2002). However, resistance to mefenoxam has been reported in $60 \%$ of $P$. ultimum isolates recovered from the greenhouse facilities evaluated in this study (Del Castillo Múnera and Hausbeck 2016). Fifty-four percent of the mefenoxam-resistant isolates that were reported in the previous study, with a range of $\mathrm{EC}_{50}$ values of mefenoxam from $197 \mathrm{up}$ to $500 \mu \mathrm{g}$ of active ingredient per milliliter (Del Castillo Múnera and Hausbeck 2016), are grouped in all the MLGs repeatedly found between fall 2011 and spring 2012+2013 (MLG.14, MLG.23, MLG.33, MLG.55, and MLG.65) and in the common ones between fall 2011 and fall 2012 (MLG.1, MLG.15, MLG.28, and MLG.47). The prevalence of these genotypes across years may suggest an established population of $P$. ultimum that is resistant to mefenoxam in Michigan greenhouses. To limit this pathogen, effective cultural practices should be implemented including the scouting and roguing of symptomatic plant material (Daughtrey and Benson 2005). Etridiazole is another chemistry that has been used commonly for Pythium root rot with good efficacy (Hausbeck et al. 2017). Newer active ingredients such as azoxystrobin and fenamidone (Del Castillo
Múnera and Hausbeck 2015; Moorman and Kim 2004) could also be considered. Biological controls agents such as Trichoderma harzianum and Streptomyces lydicus could also be implemented when disease pressure is low (Daughtrey and Benson 2005; Harman 2000; Little et al. 2003; Moorman and Kim 2004).

Historically, $P$. ultimum has been a recurrent pathogen in floriculture greenhouses (Moorman et al. 2002; Stephens and Powell 1982; Tompkins and Middleton 1950). However, based on the isolates collected and genotyped across different seasons, we were able to discern the introduction of new isolates versus resident isolates within

Table 4. Analysis of molecular variance for simple sequence repeat data of Pythium ultimum population from floriculture crops in Michigan

\begin{tabular}{lccc}
\hline Hierarchical level $^{\mathbf{a}}$ & Variation $(\boldsymbol{\%})$ & $\boldsymbol{\Phi}^{\mathbf{b}}$ & $\boldsymbol{P}$ \\
\hline Variation among counties & 5.33 & 0.05 & 0.104 \\
Variation between season within county & 2.81 & 0.02 & 0.153 \\
Variation between samples within season & 7.17 & 0.07 & 0.174 \\
Variation within samples & 84.67 & 0.15 & 0.042
\end{tabular}

${ }^{a}$ For this analysis, the data set was arranged into two hierarchical levels: county and season sampled.

${ }^{\text {b }} \mathrm{Phi}_{\mathrm{st}}(\Phi)$ calculated for different hierarchical levels, and $P$ value was estimated by 1,000 randomizations (permuting genotypes) in the respective hierarchical level.

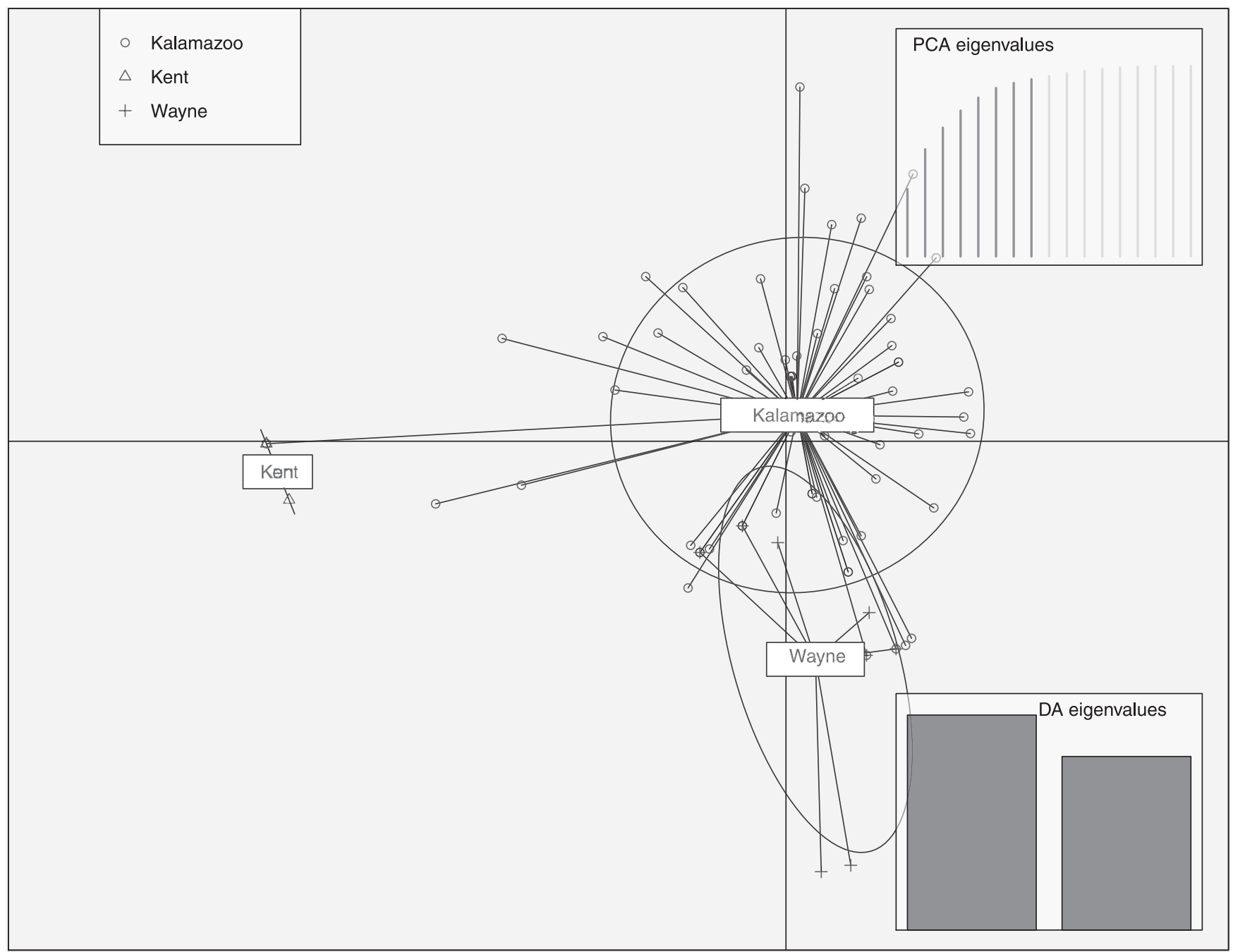

Fig. 3. Discrimination analysis of principal components (DAPC) of the first two principal components (DA eigenvalues) discriminating Pythium ultimum by location. Points represent individual observations. Lines and symbols represent population membership: Kalamazoo (circle), Kent (triangle), Wayne (plus). Ellipses represent $95 \%$ confidence interval based on a bivariate normal distribution. Inset line plot titled PCA eigenvalues represents the eight retained axes in the principal component analysis (PCA), and the bar plot represents the eigenvalues of the first two discriminant axes. 
the region. The recovery of new genotypes (eight from spring 2012+ 2013 and 17 from fall 2012) in the seasons following the fall 2011 collection may suggest the recent introduction of $P$. ultimum isolates into the greenhouses. Alternatively, it is important to consider that the recovery of new genotypes may be an artifact of sampling depth. New sources of inoculum can enter through the shipment of infected cuttings, seedlings, and prefinished plants from other greenhouse facilities, contaminated soilless medium, and/or infested tools (Parke and Grünwald 2012; Weiland et al. 2013). P. ultimum can also enter the greenhouses via irrigation water (Hong and Moorman 2005). Most of the greenhouses sampled use well water, and two greenhouses in Wayne County use city water for irrigation. Interestingly, all the greenhouses in Kalamazoo and one greenhouse in Kent County recirculate their water used for irrigation. This practice may increase the likelihood of $P$. ultimum reintroduction and may favor the presence of unique genotypes within locations. In our study, $81 \%$ of the $P$. ultimum isolates were recovered from the greenhouses that recirculate their water.

The Simpson's index scaled to size (0.938), and evenness (0.56), the recovery of 11 major clones (represented by more than three individuals) among the 65 MLGs obtained, and the presence of 11 genotypes repeatedly over the 3 years of study may suggest that there is a survival of $P$. ultimum in Michigan greenhouses. Nevertheless, to determine if the $P$. ultimum population in Michigan is established and is not a recent introduction, coalescence analysis based on sequenced data to determine the population age (Grünwald and Goss 2011) and a comparison of the genotypic diversity of $P$. ultimum populations from a different geographic origin should be performed in future studies.

The lack of population structure or differentiation among counties and the little differentiation among populations are supported by the evidence of genetic exchange among locations $(\mathrm{Nm}=3.01)$ and by the analysis of molecular variance that shows the greatest amount of variation occurs within samples rather than among counties. The presence of five common MLGs in Kalamazoo, Kent, and Wayne Counties suggests the shipment or interchange of infected plant material among greenhouses in these counties or a common source of inoculum that is being introduced to Michigan. Interestingly, MLG.10, which was only recovered in fall 2012, was present at high frequency in greenhouses in Kalamazoo and Wayne Counties. This indicates that new genotypes are being introduced into Michigan greenhouses, possibly from a common source of inoculum present in infected plant material produced elsewhere. Greenhouse growers in Michigan often import poinsettia cuttings from wholesalers located in Central America. Similar to our findings, research of the population structure of Pythium spp. (Weiland et al. 2015) and Phytophthora ramorum (Prospero et al. 2007) from forest nursery soils in Oregon showed lower genetic differentiation among populations from different nurseries and indicated that shipments of infected plant material among nurseries may contribute to pathogen dissemination (Prospero et al. 2007; Weiland et al. 2015).

In our study, the populations were defined by season, because hosts are grown in specific seasons (poinsettia and geranium are grown only in the fall and spring, respectively). The lack of differentiation among hosts, supports the non-host-specificity (Lee et al. 2010; Sutton et al. 2006), the wide range of this pathogen among ornamentals (Kucharek and Mitchell 2000; Moorman et al. 2002; Stephens and Powell 1982), and the ubiquitous nature of the Pythium genus (Martin and Loper 1999; van der Plaats-Niterink 1981).

Despite the genetic diversity detected, the index of association showed that $P$. ultimum populations in Michigan greenhouses are largely clonal. The clonality of the species supports its homothallic or self-fertile nature (Francis et al. 1994; van der Plaats-Niterink 1981). It has been shown that $P$. ultimum var. ultimum is capable of outcrossing with itself (Francis and St. Clair 1993, 1997). Francis and St. Clair (1993) reported that crosses between two P. ultimum var. ultimum isolates resulted in hybrid progeny under controlled laboratory conditions. In our study, we rejected the null hypothesis of random mating for the $P$. ultimum populations owing to the statistical significance of the index of association (average $I_{A}=1.19$ for all the individuals and 0.92 for clone-corrected data) and to the presence of 11 major clones (Fig. 1) that represent $50 \%$ of the entire population. This suggests that isolates are not undergoing outcrossing and reproduce clonally via zoospores or selfing. Similarly, the population of $P$. ultimum in Oregon was determined to be clonal (Weiland et al. 2015). Despite the clonality of the $P$. ultimum population, the genetic diversity observed (0.44) and the presence of 65 MLGs may be explained by the introduction of new genotypes that contributes to a greater genetic diversity. Also, in the Pythium genus, the presence of intraspecific variation has been reported (Chen et al. 1992; Eggertson 2012; Francis et al. 1994; Garzón et al. 2005). The recent evidence that $P$. ultimum is a species complex that encompasses four genetically distinct species (Eggertson 2012) based on multinuclear gene genealogies, $P$. ultimum, which encompasses the $P$. ultimum var. ultimum; $P$. sporangiiferum, which contains $P$. ultimum var. sporangiiferum; and two groups named Pythium sp. nov. 1 and Pythium sp. nov. 2. In our study we assume the P. ultimum sensu lato approach.

In this study, six SSRs were used to characterize the $P$. ultimum population associated with greenhouse floral crops in Michigan. The genotype accumulation curve analysis with the six SSRs showed that there was no saturation to fully discriminate ( $90 \%$ power) between individuals. The inability of the markers to discriminate between all genotypes was confirmed by $p_{\text {sex }}$ analyses, which showed that $68 \%$ of the individuals in the clone-corrected dataset were the product of clonal reproduction. This, however, still indicates that the unique genotypes show evidence for clonal structure in the absence of explicit clones.

The study of the population structure of $P$. ultimum from Michigan's greenhouse floriculture crops may impact the management strategies developed to control Pythium root rot in the region. The evidence of pathogen movement among greenhouses across the state or from a common source of inoculum coming to the region suggests that improved scouting and quick diagnostics of new plant material arriving to greenhouses should be performed. Fast and accurate diagnostic methods to detect Pythium spp. would be helpful to certify plant material (Schroeder et al. 2013). The recovery of the same pathogen genotypes across the 3 years of study suggests that greenhouse facilities should consider more effective control strategies to eradicate the $P$. ultimum population.

\section{Literature Cited}

Agapow, P. M., and Burt, A. 2001. Indices of multilocus linkage disequilibrium Mol. Ecol. Notes 1:101-102.

Arnaud-Haond, S., Duarte, C. M., Alberto, F., and Serrao, E. A. 2007 Standardizing methods to address clonality in population studies. Mol. Ecol. 16:5115-5139.

Barr, D. J. S., Warwick, S. I., and Desaulniers, N. L. 1997. Isozyme variation in heterothallic species and related asexual isolates of Pythium. Can. J. Bot. 75: 1927-1935.

Bruvo, R., Michiels, N. K., D'Souza, T. G., and Schulenburg, H. 2004. A simple method for the calculation of microsatellite genotype distances irrespective of ploidy level. Mol. Ecol. 13:2101-2106.

Chen, W., Schneider, R., and Hoy, J. 1992. Taxonomic and phylogenese analyses of ten Pythium species using isozyme polymorphisms. Phytopathology 82: 1234-1244.

Cooke, D., and Lees, A. 2004. Markers, old and new, for examining Phytophthora infestans diversity. Plant Pathol. 53:692-704.

Daughtrey, M. L., and Benson, D. M. 2005. Principles of plant health management for ornamental plants. Annu. Rev. Phytopathol. 43:141-169.

Del Castillo Múnera, J., and Hausbeck, M. K. 2015. Integrating host resistance and plant protectants to manage Pythium root rot on geranium and snapdragon. HortScience 50:1319-1326.

Del Castillo Múnera, J., and Hausbeck, M. K. 2016. Characterization of Pythium species associated with greenhouse floriculture crops in Michigan. Plant Dis. 100:569-576.

Duniway, J. 1977. Predisposing effect of water stress on the severity of Phytophthora root rot in safflower. Phytopathology 67:884-889.

Eggertson, Q. 2012. Resolving the Pythium ultimum species complex. M.S. thesis. Carleton University, Ottawa, ON.

Ellegren, H. 2004. Microsatellites: Simple sequences with complex evolution. Nat Rev. Genet. 5:435-445.

Excoffier, L., Smouse, P. E., and Quattro, J. M. 1992. Analysis of molecular variance inferred from metric distances among DNA haplotypes: Application to human mitochondrial DNA restriction data. Genetics 131:479-491. 
Francis, D. M., Gehlen, M. F., and St. Clair, D. 1994. Genetic variation in homothallic and hyphal swelling isolates of Pythium ultimum var. ultimum and P. ultimum var. sporangiferum. Mol. Plant-Microbe Interact. 7:766-775.

Francis, D. M., and St. Clair, D. A. 1993. Outcrossing in the homothallic oomycete, Pythium ultimum, detected with molecular markers. Curr. Genet. 24:100-106.

Francis, D. M., and St. Clair, D. A. 1997. Population genetics of Pythium ultimum. Phytopathology 87:454-461.

Garzón, C., Sain, L., Garrido, P., Sanchez, I., Garces, G., Espinosa, P., Medina, A., Proano, F., Cornejo, F., and Daughtrey, M. 2014. Population dynamics of Pythium species in floricultural greenhouses in Long Island, New York. Phytopathology 104(Suppl. 3):S3.44-S3.45.

Garzón, C. D., Geiser, D. M., and Moorman, G. W. 2005. Amplified fragment length polymorphism analysis and internal transcribed spacer and coxII sequences reveal a species boundary within Pythium irregulare. Phytopathology 95:1489-1498.

Garzón, C. D., Molineros, J. E., Yánez, J. M., Flores, F. J., Del Mar JiménezGasco, M., and Moorman, G. W. 2011. Sublethal doses of mefenoxam enhance Pythium damping-off of geranium. Plant Dis. 95:1233-1238.

Ghimire, S., Richardson, P., Moorman, G., Lea-Cox, J., Ross, D., and Hong, C. 2009. An in-situ baiting bioassay for detecting Phytophthora species in irrigation runoff containment basins. Plant Pathol. 58:577-583.

Grünwald, N. J., Goodwin, S. B., Milgroom, M. G., and Fry, W. E. 2003. Analysis of genotypic diversity data for populations of microorganisms. Phytopathology 93:738-746.

Grünwald, N. J., and Goss, E. M. 2011. Evolution and population genetics of exotic and re-emerging pathogens: Novel tools and approaches. Annu. Rev. Phytopathol. 49:249-267.

Grünwald, N. J., and Hoheisel, G.-A. 2006. Hierarchical analysis of diversity, selfing, and genetic differentiation in populations of the oomycete Aphanomyces euteiches. Phytopathology 96:1134-1141.

Guichoux, E., Lagache, L., Wagner, S., Chaumeil, P., Léger, P., Lepais, O., Lepoittevin, C., Malausa, T., Revardel, E., and Salin, F. 2011. Current trends in microsatellite genotyping. Mol. Ecol. Resour. 11:591-611.

Harman, G. E. 2000. Myths and dogmas of biocontrol changes in perceptions derived from research on Trichoderma harzinum T-22. Plant Dis. 84:377-393.

Hausbeck, M. K., and Harlan, B. 2013. Pythium root rot in the greenhouse. Michigan State University Extension, East Lansing. http://www.canr.msu. edu/news/pythium_root_rot_in_the_greenhouse. Accessed December 2013.

Hausbeck, M.k.Harlan, B., and Linderman, S. 2017. P is for Pythium root rot on ornamentals. Michigan State University Extension, East Lansing. http:// www.canr.msu.edu/news/pythium_root_rot_on_ornamentals. Accessed September 2017.

Hayden, M., Nguyen, T., Waterman, A., Mcmichael, G., and Chalmers, K. 2008. Application of multiplex-ready PCR for fluorescence-based SSR genotyping in barley and wheat. Mol. Breed. 21:271-281.

Hong, C., and Moorman, G. 2005. Plant pathogens in irrigation water: Challenges and opportunities. Crit. Rev. Plant Sci. 24:189-208.

Jombart, T. 2008. adegenet: A R package for the multivariate analysis of genetic markers. Bioinformatics 24:1403-1405.

Kamvar, Z. N., Tabima, J. F., and Grünwald, N. J. 2014. Poppr: An R package for genetic analysis of populations with clonal, partially clonal, and/or sexual reproduction. PeerJ 2:e281.

Kucharek, T., and Mitchell, D. 2000. Diseases of agronomic and vegetable crops caused by Pythium.Plant Pathology Fact Sheet PP53. Institute of Food and Agricultural Sciences, University of Florida, Gainesville.

Lee, S., Garzón, C. D., and Moorman, G. W. 2010. Genetic structure and distribution of Pythium aphanidermatum populations in Pennsylvania greenhouses based on analysis of AFLP and SSR markers. Mycologia 102: 774-784.

Lévesque, C. A., Brouwer, H., Cano, L., Hamilton, J. P., Holt, C., Huitema, E., Raffaele, S., Robideau, G. P., Thines, M., and Win, J. 2010. Genome sequence of the necrotrophic plant pathogen Pythium ultimum reveals original pathogenicity mechanisms and effector repertoire. Genome Biol. 11: R73.

Li, Y., Cooke, D., Jacobsen, E., and Van Der Lee, T. 2013. Efficient multiplex simple sequence repeat genotyping of the oomycete plant pathogen Phytophthora infestans. J. Microbiol. Methods 92:316-322.

Linde, C., Zhan, J., and McDonald, B. 2002. Population structure of Mycosphaerella graminicola: From lesions to continents. Phytopathology 92: 946-955

Little, M., Brown, W., Blom, T., Gracia-Garza, J., Schneider, K., Allen, W., and Potter, J. 2003. Efficacy of various biological control agents and biorationals against Pythium root rot in poinsettia. HortTechnology 13:149-153.

Lookabaugh, E., Ivors, K., and Shew, B. 2015. Mefenoxam sensitivity, aggressiveness, and identification of Pythium species causing root rot on floriculture crops in North Carolina. Plant Dis. 99:1550-1558.
Ludwig, J. A. 1988. Statistical Ecology: A Primer in Methods and Computing Wiley, Hoboken, NJ

Martin, F. N. 2000. Phylogenetic relationships among some Pythium species inferred from sequence analysis of the mitochondrially encoded cytochrome oxidase II gene. Mycologia 92:711-727.

Martin, F. N., and Loper, J. E. 1999. Soilborne plant diseases caused by Pythium spp.: Ecology, epidemiology, and prospects for biological control. Crit. Rev. Plant Sci. 18:111-181.

Matschiner, M., and Salzburger, W. 2009. TANDEM: Integrating automated allele binning into genetics and genomics workflows. Bioinformatics 25:1982-1983.

McDonald, B. A., and Linde, C. 2002. Pathogen population genetics, evolutionary potential, and durable resistance. Annu. Rev. Phytopathol. 40:349-379.

Milgroom, M. G. 1996. Recombination and the multilocus structure of fungal populations. Annu. Rev. Phytopathol. 34:457-477.

Moorman, G., Kang, S., Geiser, D., and Kim, S. 2002. Identification and characterization of Pythium species associated with greenhouse floral crops in Pennsylvania. Plant Dis. 86:1227-1231.

Moorman, G., and Kim, S. 2004. Species of Pythium from greenhouses in Pennsylvania exhibit resistance to propamocarb and mefenoxam. Plant Dis. 88:630-632.

Nei, M. 1978. Estimation of average heterozygosity and genetic distance from a small number of individuals. Genetics 89:583-590.

Parke, J. L., and Grünwald, N. J. 2012. A systems approach for management of pests and pathogens of nursery crops. Plant Dis. 96:1236-1244.

Peakall, R., and Smouse, P. E. 2012. GenAlEx 6.5: Genetic analysis in Excel. Population genetic software for teaching and research-An update. Bioinformatics 28:2537-2539.

PGRC. 2002. Microsatellite Identification Tool. http://pgrc.ipk-gatersleben. $\mathrm{de} / \mathrm{misa} /$.

Prospero, S., Hansen, E., Grünwald, N., and Winton, L. 2007. Population dynamics of the sudden oak death pathogen Phytophthora ramorum in Oregon from 2001 to 2004. Mol. Ecol. 16:2958-2973.

Robideau, G. P., de Cock, A. W., Coffey, M. D., Voglmayr, H., Brouwer, H., Bala, K., Chitty, D. W., Désaulniers, N., Eggertson, Q. A., Gachon, C. M., and $\mathrm{Hu}, \mathrm{C}$. H. 2011. DNA barcoding of oomycetes with cytochrome c oxidase subunit I and internal transcribed spacer. Mol. Ecol. Resour. 11:1002-1011.

Rozen, S., and Skaletsky, H. 1999. Primer3 on the WWW for general users and for biologist programmers. Pages 365-386 in: Bioinformatics Methods and Protocols. Methods in Molecular Biology, vol. 132. S. Misener and S. A. Krawetz, eds. Humana Press, Totowa, NJ.

Schroeder, K. L., Martin, F. N., De Cock, A. W., Lévesque, C. A., Spies, C. F. Okubara, P. A., and Paulitz, T. C. 2013. Molecular detection and quantification of Pythium species: Evolving taxonomy, new tools, and challenges. Plant Dis. 97:4-20.

Stephens, C., and Powell, C. 1982. Pythium species causing damping-off of seedling bedding plants in Ohio greenhouses. Plant Dis. 66:731-733.

Stoddart, J. A., and Taylor, J. F. 1988. Genotypic diversity: Estimation and prediction in samples. Genetics 118:705-711.

Sutton, J. C., Sopher, C. R., Owen-Going, T. N., Liu, W., Grodzinski, B., Hall, J. C. and Benchimol, R. L. 2006. Etiology and epidemiology of Pythium root rot in hydroponic crops: Current knowledge and perspectives. Summa Phytopathol. 32:307-321

Tompkins, C. M., and Middleton, J. T. 1950. Etiology and control of poinsettia root and stem rot caused by Pythium spp. and Rhizoctonia solani. Hilgardia 20:171-182.

USDA. 2016a. Floriculture crops 2015 summary. http://usda.mannlib.cornell.edu/ usda/current/FlorCrop/FlorCrop-04-26-2016.pdf. Accessed August 2018.

USDA. 2016b. Michigan floriculture sales ranked third nationally. https://www nass.usda.gov/Statistics_by_State/Michigan/Publications/Ag_Across_Michigan/ 2016/aam1605.pdf. Accessed August 2018.

van der Plaats-Niterink, A. J. 1981. Monograph of the Genus Pythium. Studies in Mycology no. 21. Centraalbureau voor Schimmelcultures, Baarn, the Netherlands.

Weiland, J., Garrido, P., Kamvar, Z. N., Espindola, A. S., Marek, S., Grünwald, N. J., and Garzon, C. D. 2015. Population structure of Pythium irregulare, P. ultimum, and $P$. sylvaticum in forest nursery soils of Oregon and Washington. Phytopathology 105:684-694.

Weiland, J. E., Beck, B. R., and Davis, A. 2013. Pathogenicity and virulence of Pythium species obtained from forest nursery soils on Douglas-fir seedlings Plant Dis. 97:744-748.

White, T. J., Bruns, T., Lee, S., and Taylor, J. 1990. Amplification and direct sequencing of fungal ribosomal RNA genes for phylogenetics. Pages 315-322 in: PCR Protocols: A Guide to Methods and Applications. Academic Press, San Diego, CA.

Yeh, F. C., Yang, R. C., Boyle, T. B., Ye, Z., and Mao, J. X. 1997. Page 10 in: POPGENE, the user-friendly shareware for population genetic analysis Molecular Biology and Biotechnology Centre, University of Alberta, Canada. 